\title{
UMA CARTA SINCERA AOS COLEGAS DO DIREITO
}

Queridos colegas,

Desde que recebi o meu diploma em Direito, muitos amigos que ainda estão na universidade - e apreensivos com suas próprias formaturas - perguntam-me como é a vida de formada. Outro dia, no grupo de Whatsapp da minha turma da graduação, um colega perguntou-me o que nós estávamos fazendo em nossa vida profissional. Depois, pediram-me um texto relatando a minha experiência enquanto egressa, abordando o final do curso e o começo da carreira. Eu aceitei, contudo, logo em seguida, me perguntei: “O que tenho para falar?".

Essas indagações são frequentes após você se formar na faculdade. Os outros perguntam e nós nos questionamos também: “O que estou fazendo da vida?”.

Aviso, desde já, que o início da minha trajetória profissional não está sendo como eu desejaria, tampouco, está próximo do que os profissionais do meio jurídico consideram "bom”, “ideal” ou "um sucesso". Isso me faz indagar se o problema está em mim ou neste "nicho de mercado".

Assim, decidi escrever uma carta em completa honestidade, mesmo correndo o risco de ser julgada por falar abertamente de questões que são muito comuns na carreira de um jurista recém-formado - mas que poucas pessoas falam à respeito, ou assim penso. Tentarei fugir dos estereótipos e não soar frustrada, arrependida e raivosa, embora estes sentimentos sejam constantes após a formatura. Eu apenas desejo falar de modo franco e simples da minha experiência, na esperança de que alguém que leia se identifique e que possamos tentar superar esse lado ruim da situação falando sobre ela, e não nos convencendo erroneamente de que está tudo bem. Meu intuito não é assustar, mas ser verdadeira, mesmo que a verdade incomode e exponha problemas que muitos anseiam em esconder, seja qual for o motivo.

Acredito que já tenha passado muito tempo me justificando. Perdão, tenho mania de argumentação e justificativa.

Minha experiência nos semestres finais do curso de Direito foi semelhante à de outros colegas com quem conversei na época, colegas estes que estavam em uma situação similar à minha. A vontade de encerrar de vez o curso por estarmos cansados de longas aulas - que nem sempre eram proveitosas -, provas, estágios, Exame da Ordem, TCC, cobranças pessoais e de terceiros... Direito é um curso longo, e assomado às greves no ensino público, fica mais longo ainda. Saúde mental debilitada também era um fator em particular: dentre causas menores, as crises de depressão e ansiedade começaram no final do curso por questões relacionadas ao 
bacharelado e/ou alimentadas por elas. Resumiam-se em uma mescla de problemas na vida acadêmica e temor pelo futuro profissional que se somavam aos problemas da vida pessoal.

Mas também era um momento que se suscitou em mim a vontade de terminar essa fase e começar um ciclo novo, no qual pudesse ter muitas possibilidades profissionais e pessoais. Quem não anseia, ao terminar um curso de graduação, conseguir o emprego dos sonhos, cursar um mestrado ou especialização, casar, ter filhos, viajar, estudar para concursos, mudar de cidade ou voltar para a cidade natal, certo?

Assim como eu, penso que muitos colegas tinham a sensação de estarem esgotados, mas, ao mesmo tempo, possuíam esperança nas perspectivas futuras. Havia os questionamentos também. Deveria eu fazer o que todo mundo faz quando se forma em Direito? Conseguiria fazer o que todo mundo faz? O que todo mundo faz era o que eu queria? Seria bom para mim? Traria satisfação e realização? Olhando para trás, vejo que, em 2019, quando me formei, não havia de imaginar como eu estaria hoje, em 2020.

Com meu diploma numa mão e a carteira da OAB na outra, eu não sabia o que fazer. Feliz, talvez, seja quem já tem o caminho traçado antes mesmo de terminar o curso. Especialmente no Direito, acho que existem muitos com escritório montado, um leque de clientes à espera, familiares cedendo causas, clientes que pagam o acordado como fora acordado, cargo comissionado em vista, estrutura para estudar para concurso e/ou trabalhar, etc. Mas eu não era um desses, então tinha que pensar no que iria fazer quando me formasse. Eu havia mudado de cidade para cursar Direito, como muitos outros colegas de curso, porém, depois da formatura, fiz a escolha pessoal de não voltar a morar com minha família.

Decidi fazer uma seleção de mestrado. Eu gostaria de dizer que foi uma experiência apenas enriquecedora e cheia de aprendizado, entretanto estou prezando por sinceridade nessa carta. A seleção foi repleta de ansiedade, cobranças e a sensação indelével de não ser inteligente o suficiente. Uma banca de seleção de mestrado não é algo que te deixa contente por ter cursado Direito. De fato, a partir da minha experiência e de outros colegas, percebi que a seleção de mestrado te faz questionar o porquê de você ter cursado Direito, e se esse é o ambiente que você deveria estar. Questionei-me até das coisas que acreditava adorar naárea.

Após as crises existenciais, a escrita do projeto e a tentativa de convencer pessoas que não desejam serem convencidas da relevância de sua pesquisa, eu passei no mestrado. Quando comentava da aprovação, parecia que havia sido escolhida para uma espécie de elite, um grupo seleto de pessoas que estão acima e são diferenciadas dos meros bacharéis em Direito.

Realmente, esse grupo é muito diferenciado. É uma elite da qual não me encaixo até hoje, quase um ano após a seleção. Não possuo emprego, carro ou clientes, sequer fui aprovada em concursos públicos. Não frequento os melhores bares e restaurantes da cidade, tampouco passei férias na Europa. O que os meus colegas pesquisam no mestrado parece fundamentar que a minha pesquisa não é relevante. É o ônus de ter quebrado as barreiras das desigualdades e estar perto de uma elite que não dialoga com você, que não te enxerga, que não se parece com você, que não quer abrir a cabeça para ouvir o que você pensa.

Ainda assim, passei no mestrado. Tudo deveria, em tese, melhorar: eu teria mais oportunidades, iria 
me aperfeiçoar, faria o famigerado networking. Esse era o plano, mas não tem funcionado muito para mim até agora.

Primeiramente, eu precisava de uma fonte de renda, afinal tenho contas para pagar e minha família não possui dinheiro para essas despesas. Passei a maior parte da graduação me sustentando com o dinheiro da bolsa do estágio, morando na residência estudantil e tentando não pedir ajuda a minha família, porque a situação era complicada para eles.

Meu receio, assim, era como eu conseguiria dinheiro após o fim do estágio. Logo depois da colação de grau, em 2019, eu entrei no mestrado, portanto poderia me candidatar para uma das bolsas disponíveis. Entretanto, naquele ano, não havia vagas para financiar o estudo científico dos pesquisadores, especialmente daqueles que pesquisam sobre direitos humanos, gênero, políticas públicas e cotas para minorias.

Sendo assim, comecei pelo caminho mais fácil: fazer o que todo mundo faz. Fiz seleções para a chamada residência, o estágio de pós-graduação, com breve consciência dos problemas que iria encarar, que não seriam diferentes dos no estágio na graduação - talvez apenas mais desafiadores. No estágio de pós há o espaço para aprendizagem e ganho de experiência, mas isso vem junto da precarização do trabalho, da exploração de uma mão de obra barata e vulnerável, do excesso de responsabilidades - o que não é, necessariamente, culpa dos supervisores e gestores, mas sim do sistema e da organização judiciária em nossa região.

O estágio de pós-graduação me deixou feliz por um tempo, mas minha saúde mental, que estava ainda mais debilitada, não aguentava a frustração de ser somente uma estagiária, mesmo com diploma na mão. A sensação que costumeiramente me perseguia era a de que eu não tinha terminado o ciclo da faculdade e estava empacada, sem avançar para lugar algum. Durante a graduação, sempre quis advogar, portanto decidi largar o estágio para realizar esse desejo. Não tem dado muito certo até hoje. Envio currículos para escritórios, procuro vagas diariamente, realizo entrevistas que não dão em nada.

Parece-me que desejam contratar um advogado "júnior", mas que tenha vasta experiência e que aceite receber $\mathrm{R} \$ 2.000,00$ por mês. O próprio estágio de pós-graduação paga isso e chego a sentir saudade, porque, para conseguir a vaga, você não depende de questões como a discricionariedade dos recrutadores, o sobrenome da sua família, a indicação de pessoas influentes ou a sua “aparência de sucesso e competência".

Estou tentando advogar e, em tempos de isolamento social, somente me resta procurar vagas homeoffice, fazer cursos online para aprimorar o currículo e pedir o auxílio alimentação lançado pela OAB. Já os clientes, esses até aparecem, mas a maioria quer tirar dúvidas e não pagar por tal. Além do mais, mesmo quando há pagamento, os honorários demoram e o problema é que "eu preciso comer hoje, e não em setembro" (Atlanta, $1^{\text {a }}$ temporada, 2016). Quando tudo passar e as aulas do mestrado voltarem, eu vou precisar de dinheiro para almoçar na faculdade, pagar o ônibus para me deslocar até lá, arcar com aluguel, internet, luze água.

Enquanto isso, eu vejo dicas para conseguir pavimentar o caminho da minha vida profissional, afinal, no meio jurídico, você precisa aparecer e parecer ter sucesso. As roupas, os saltos, a maquiagem, o cabelo 
"arrumado" e o carro novo - de preferência um modelo não popular -, todos importam. Prefiro, inclusive, nem entrar na discussão sobre o custo de tudo isso, afinal, estou pensando em como fazer para comprar comida ainda.

No campo jurídico, você precisa parecer. Parecer competente - mesmo que não seja - e ter sucesso mesmo que não tenha -, porque as pessoas verão o quão bem sucedido e competente você "é" e, então, somente por isso, concluirão que você deve ser bom no que faz, embora você não faça nada. Isso é uma crítica, mas também uma confissão. Quem não faz esse tipo de coisa? Na era das redes sociais, quem não tenta parecer feliz e bem-sucedido nas coisas que posta? O mundo dos juristas não é diferente. O problema está em vender o sucesso sem falar dos percalços enfrentados, como se fosse igualmente fácil-ou difícil-para todo mundo.

Eu tenho capacidade e conhecimento, pois minha formação acadêmica foi boa, estagiei por muito tempo, participei de atividades extracurriculares como projetos de extensão e de pesquisa, fui aprovada no Exame da OAB sem sufoco - apesar da pressão agoniante -, passei em um mestrado... mas me parece que tudo isso ainda não é o suficiente.

Tentar me encaixar nesse universo do Direito é o que faço desde que entrei na graduação e ainda não consegui. Todo estudante de Direito se questiona se o caminho que está tomando é o certo. Seria a área a errada? Deveria focar numa com mais oportunidades, sob pena de não gostar? São questões que me perturbam ainda hoje, um ano depois da minha colação de grau.

Hoje, vejo que é normal se sentir perdida com esses aspectos da carreira, ainda mais no começo de um caminho que estamos trilhando. É comum se sentir um fracasso por não ter atingindo - ou por não quereras metas que dizem ser ideais. Quem me dera ter a segurança dos profissionais que já estão há anos no mercado. Provavelmente eles já passaram pelas angústias que estou passando e, talvez, só estão bem porque já as superaram, de um modo ou de outro.

Ainda me pergunto sobre a razão de não me encaixar nesse mundo dos juristas, e sei que não é por causa do Direito em si, porque eu gosto do Direito - não de todas as searas, mas de algumas, o que é perfeitamente normal. Talvez o problema sejam algumas pessoas e convenções que existem neste seio social. Por isto precisamos falar sobre essas questões: tentar superar, compreender os outros, dar oportunidades, ser solidários, buscar uma nova perspectiva - ainda que a "mão velada" deste mercado dificulte.

Mesmo diante do exposto, nem tudo está perdido. Não estou desistindo do Direito, a área que escolhi. Quero advogar, gosto da pesquisa científica, particularmente das pesquisas empíricas, que procuram refletir as problemáticas sociais existentes no campo jurídico e como elas afetam os seus diversos sujeitos. Essa questão sempre me instigou, não é à toa que escrevi esse texto ou que minha dissertação aborda este tema.

Eu defendo que o mundo jurídico, em suas diversas vertentes - academia, advocacia, judiciário, etc. -, deve repensar suas práticas e as consequências dessas para a sociedade, especialmente no que diz respeito àqueles que estão diretamente envolvidos, quem comumente chamamos de "operadores do Direito". Professores, magistrados, discentes, universidades, OAB, advogados, pesquisadores, dentre outros, que 
podem ser agentes de mudanças positivas na área.

Esta é a visão do Direito que eu aprendi durante a formação crítica que tive na graduação compartilhando-a com professores, colegas de curso, chefes e outros funcionários nos espaços em que estagiei - e pela qual sou grata, pois ela revolucionou completamente a minha maneira de enxergar o mundo e a minha própria vida. Acredito que todo aprendizado é, portanto, uma espécie de revolução.

Essa sou eu, nesta carta, apenas tecendo minhas críticas a esse universo jurídico e àqueles que o compõem, expondo as brechas no discurso meritocrático do "você tem que se esforçar" - discurso este que nem sempre funciona, especialmente para quem veio das camadas mais baixas da sociedade e vem ocupando, há poucos anos, os mesmos bancos que a elite ocupa há séculos. Estou relatando, sinceramente, o que, para mim, não tem sido fácil, desde o final do curso até agora, no começo da vida profissional.

Encerro dizendo que meu objetivo com estas linhas não é desmotivar, tampouco parecer amarga e desacreditada. Mas não quis escrever um texto lindo, ilusório e irreal. Preferi mostrar os percalços da minha vivência, mesmo sentindo que isso me expõe, para que aquelas pessoas que se encontrem na mesma posição que estou hoje não se sintam sozinhas e, principalmente, não desanimem. Não é fácil, mas se cheguei até aqui, sei que não é impossível. 